\title{
Exégesis y antropología parental Un estudio introductorio a adelphós en el Nuevo Testamento
}

\author{
ANTONIO LEBEO GUZMÁN RAYA* \\ Universidad Michoacana de San Nicolás de Hidalgo (México) \\ antuanmagno@gmail.com
}

\begin{abstract}
Resumen
El estudio del empleo de la palabra adelphos ("hermano") en el Nuevo Testamento en las últimas décadas ha tendido a un consenso donde se favorece la perspectiva literal en la cual se asocia a Jesús de Galilea "hermanos" carnales, según los testimonios de los textos griegos. Sin embargo, desde otra perspectiva como la antropología del parentesco y la historia social parental, los datos que atestigua el Nuevo Testamento no son unívocos y se interpelan a la luz de la estructura familiar exogámica extendida — aspecto crucial - para señalar que los textos aportan datos e información, pero no son en sí la respuesta. A lo cual, se abre una perspectiva más rica en matices y aspectos del parentesco de Jesús y los lazos parentales en Galilea del siglo I d.C.

Palabras claves: parentela de Jesús, familia exogámica, patriarcado, hermanos de Jesús.

\section{Exegesis and parental anthropology An introductory study of 'adelphós' in the New Testament}

\begin{abstract}
The critical historical study of adelphos ("brother") in recent decades has tended to a consensus that favors the perspective in which Jesus of Galilee is recognized as "carnal brothers", according to the testimonies of the Greek texts. However, from the parental anthropology and the socialparental history, the data attested by the new testament are not univocal and are addressed in the light of the extended exogamous family structure, a crucial aspect, to point out that the texts provide data and information, but they are not the answer in itself. To which, a richerperspective opens in nuances and aspects of the kinship of Jesus and the parental ties in Galilee of the 1st century $A D$.
\end{abstract}

Key words: kinship of Jesus, exogamous family, patriarchy, brothers of Jesus.

Profesor del Instituto San Lucas (Tarimbaro, Michoacán, México) y de bachillerato Instituto Edith Stein (Morelia, Michoacán). M. en C. en desarrollo local, UMSNH. 


\section{INTRODUCCIÓN}

Los exegetas en las últimas décadas han venido pronunciando un consenso acerca de la naturaleza y alcance de la palabra $\alpha \delta \varepsilon \lambda \varphi \rho \varsigma$ ("hermano" adelphós $)^{1}$ con respecto a la parentela de Jesús. Uno de los estudios, entre otros, que ha reflejado dicho consenso es la obra de Meier (1998). En su primer tomo de Un judio Marginal, Meier concluye, después de un exhaustivo análisis histórico crítico, que no hay razones exegéticas ni filológicas que permitan señalar que la palabra adelphós "hermano" (âh, en hebreo, y $\hat{a} h \hat{a}$, en arameo) en el Nuevo Testamento (NT) pueda utilizarse como sustitución o referencia de anepsiós (primo) ${ }^{2}$. Así, también, Luz (2001), en su comentario al Evangelio según san Mateo, comenta, "Filológicamente la cuestión es clara", relacionándolo a una cuestión de dogmas y políticas eclesiales (Luz, 2001: 511-512).

Sin embargo, aunque los argumentos de Meier y Luz han sido considerados como concluyentes por la mayoría de los estudiosos, realizando un análisis desde otro campo, igualmente competente para el estudio bíblico e histórico (Douglas, 2006; Malina, 2002), como lo es la antropología parental, la perspectiva aparece más amplia y matizada, una vez que se consideran la estructura familiar y la unidad doméstica judía de dicho tiempo. Es decir, que los argumentos de orden exegético y principalmente filológicos no pueden abordar el problema en toda su dimensión. No se trata, entonces, de hacer una revisión solamente de los argumentos de los exégetas, sino, ubicar desde un enfoque parental antropológico los lazos familiares de Galilea en el siglo I de nuestra era.

Como el título de esta investigación señala, se trata de un análisis introductorio, para lo cual, se analizan algunos textos griegos donde aparece la palabra adelphós para señalar sus polivalencias ${ }^{3}$. Se introducirá una caracterización, sin ser rigurosa, más bien, descriptiva (introductoria) sobre algunos elementos de la estructura familiar exogámica extendida judía del siglo I.

Con ello se intenta rescatar o abrir una vía de estudio poco abordada

\footnotetext{
$1 \alpha \delta \varepsilon \lambda \varphi \circ \varsigma$, adelphós, denota hermano en forma plural. Sin embargo, también es $\alpha \delta \varepsilon \lambda$ pors (hermanos) y en femenino adelphé (hermana).

2 Con ello se comprobaría el argumento que, desde San Jerónimo, ha pronunciado la Iglesia Católica sobre la interpretación de la palabra adelphós corresponde a una parentela cercana, no "hermanos" literales, siendo así se vendría abajo o estarían muy debilitados los argumentos teológicos de una perpetua virginidad de María, y solo se podría defender con el dogma, pero desencarnados de la historia y la investigación bíblica.

3 Dicho trabajo ha sido bastante estudiado por la exégesis; véase, García (1995) y Meier (1998). Aquí se realiza un nuevo análisis señalando algunos detalles que no han sido esclarecidos por los especialistas.
} 
por la crítica bíblica del Nuevo Testamento, que es lo referente a la antropología parental, que ha realizado avances muy significativos con respecto a problemas de filología en núcleos familiares extendidos donde el empleo de palabras como "hermano" se vuelve difusa. Lo anterior no solo ha sido presentado en núcleos familiares semitas de la antigüedad, sino que es un fenómeno extendido de forma general en los pueblos antiguos y la mayoría de tribus aborígenes.

Con lo anterior se intenta dar una nueva apertura al problema de cómo podemos entender las apariciones en el Nuevo Testamento de los "adelphós” de Jesús, no desde una perspectiva figurada, analógica o teológica, sino ir al centro de la cuestión. Los exégetas que han dado sus conclusiones no han abordado, comúnmente, aspectos que dentro de las ciencias bíblicas se han introducido en los últimos años. En ese sentido, la cuestión principal es contrastar los datos del Nuevo Testamento y extra neo estamentales para comprender los lazos parentales de Jesús. Se realiza una investigación lo más objetiva posible, aunque los testimonios, como se observará, no corresponden a una simple cuestión de dogmas y políticas eclesiales como sugiere la exégesis protestante, independiente y algunos católicos.

La investigación parte de la interrogante: ¿cómo comprender y situar la dinámica parental exogámica judía a través de los testimonios del Nuevo Testamento? El problema, es precisamente que los testimonios son muy escasos y de distinta comprensión, porque corresponden a una etapa redaccional u oral que se insertan en un entorno y situación específica, al cual no tenemos acceso. El marco teórico y metodológico que mejor se presenta para dicho caso es la antropología del parentesco. Si bien no se plantean soluciones concluyentes, se abren nuevos argumentos y problemas para enfocar el estudio del parentesco en tiempos de Jesús.

El estudio se divide en dos partes, un análisis y discusión de los textos y la palabra adelphós tal como se presentan en el Nuevo Testamento, de manera especial, en los evangelios, en las cartas paulinas y otros textos como son en Flavio Josefo y en Hegesipo. La segunda parte consta de una conceptualización de la antropología judía y cristiana del siglo I d. C. como elemento de rehabilitación de los textos antes estudiados. Se termina con las conclusiones.

1. EL USO DE ADELPHÓS (“HERMANO”) EN LOS EVANGELIOS Y OTROS TEXTOS

El uso de $\alpha \delta \varepsilon \lambda \varphi o \varsigma$ (adelphós=hermano) en el Nuevo Testamento (NT) y especialmente en la Biblia griega (LXX) como una posible traducción de 
âh (hermano en hebreo), ha sido un tema ampliamente discutido ${ }^{4}$. En la actualidad, existe cierto consenso que se puede resumir así: No hay bases suficientes para sostener filológica y exegéticamente que el uso de adelphós es un término, en sentido amplio, que pueda expresar de manera correcta o similar la palabra "primo" o "pariente" 5 . Los argumentos que soportan dicho análisis se basan en la comparación de los textos de la Biblia griega de los LXX con la Biblia hebrea ${ }^{6}$ (Tanak). De manera particular el estudio de los evangelios sobre el uso de adelphós (hermano) como el de anepsiós (primo), se complementa con los testimonios escritos de Flavio Josefo, principalmente, en las Antigüedades Judías, por hacer mención del "hermano de Jesús" (Santiago), en el testimonio de Hegesipo obispo de Jerusalén, según lo encontramos en la Historia Eclesial de Eusebio de Cesárea y en las cartas auténticas de Pablo (Ga; $1 \mathrm{Co}$ ), estos últimos testimonios saben distinguir en el empleo del griego entre el uso de "hermano" y "primo". Incluso escriben de acuerdo a su pensamiento y no a una traducción del hebreo o del arameo al griego, como ha sido tradicionalmente defendido desde san Jerónimo en el empleo de la traducción de la Biblia hebrea a la de los LXX.

Lo anterior, no agota el tema sobre la ausencia o presencia de "hermanos carnales" con relación a Jesús de Nazaret, hay otros elementos como, por ejemplo, el pasaje de Mt 1, 25 donde la controversia se basa en el uso de la expresión "hasta que"7 . Sin embargo, este estudio se centrará únicamente en el uso del término adelphós ("hermano") (García, 1995: 3) en el NT y extra-neotestamentales.

El uso de adelphós en el NT se emplea de dos formas, 1) de manera literal (hermano sanguíneo o biológico de la misma madre) y 2) figurativo o analógico. "Se llaman entre sí hermanos los seguidores de Jesús (Mc 3, 35), los cristianos de la iglesia primitiva (1 Co 1, 1; 5, 11), los judíos (Hch 2, 29; Rm 9, 3; Mt 7, 3-5 llama hermano a cualquier vecino), los seres humanos (Hb 2, 11-17)" (García, 1995: 3; también ver Luz, 2001: 509, nota 15).

4 Lo que se ha discutido, es que si el uso de adelphós puede ser una traducción fiel de âh, hay que considerar que âh es un término polivalente. Una buena pregunta sería ¿cómo se traduciría âh en la actualidad a las lenguas vernáculas? Si consideramos que en la actualidad en las lenguas del medio oriente sigue existiendo esa polivalencia. Hoy cualquier hebraísta sabe que la lengua hebrea es pobre en expresiones lingüísticas, en especial a las familiares como "hermano".

5 Postura defendida por Meier (1998); Brown (1978); García (1995: 16-31). Aunque no todos comparten dicha postura, por ejemplo, Ruiz (1994: 51-70).

6 Para una revisión de los pasajes bíblicos que se comparan véase, Meier (1998: 301340); Tuggy (1996: 26).

7 Para ver los criterios que se consideran en señalar que Jesús tuvo "hermanos" carnales; véase, Meier (1998). 
Según Meier, el argumento de que en la Biblia se utiliza el término adelphós ("hermano") y anepsiós ("primo") de manera indistinta carece de bases filológicas sólidas (Meier, 1998: 298-359; Luz, 2001: 509, nota 15) ${ }^{8}$. Cabe señalar que dichos aspectos no se remiten sólo a los textos judíos, en textos romanos y griegos antiguos se llega a usar de forma indistinta los términos primo y hermano, por ejemplo, en algunas obras de Cicerón (Las metamorfosis) y Ovidio (Ruíz, 1994). Dicha problemática filológica, en especial, con los lazos de hermandad, para los antropólogos y etnólogos es un tema recurrente, en muchas culturas y pueblos históricos se usa de manera indistinta el término hermano cuando se hace clara referencia a primo hermano o prima hermana (Aranzadi, 2008; González, 2017; Durkheim, 2012).

Siendo así, se propone un análisis concreto del término adelphós como se encuentra en los distintos textos neotestamentales y extra-testamentales, para después realizar un análisis con los datos históricos y antropológicos del entorno de la sociedad patriarcal en el que se desenvolvió el uso de adelphós en los evangelios.

\subsection{El uso adelphós en Flavio Josefo, Hegesipo y Pablo}

Un posible balance empezando por Flavio Josefo en las Antigüedades Judías (20.9.1) habla de Santiago el "hermano" de Jesús. Considerando que Josefo es muy cuidadoso en distinguir entre hermano, primo y parientes. Sin embargo, de dicha expresión lo primero que resalta, en contraste, es que en el Nuevo Testamento no hay ningún texto en que se aplique la expresión "hermano" de Jesús para designar a Santiago con relación a Jesús, siendo más bien, la fórmula como el "hermano" del Señor (Ga 1,19). Una posible explicación es que Josefo lo pone como Jesús y no como Señor por las posibles connotaciones políticas-religiosas (Señor $=$ Mesías y como referencia a un ser pre-existente), cuestión que para Josefo es evidente, Jesús no es el Mesías, mucho menos el Hijo de Dios en la línea del profeta Daniel. Por lo cual, García, al respecto comenta:

El Nuevo Testamento habla de "hermanos del Señor", no de "hermanos de Jesús". Da la impresión de que en el lenguaje del Nuevo Testamento se pretende hablar de algo más que una relación física de fraternidad con Jesús.

\footnotetext{
8 Aunque otros autores como Ruiz (1994), argumentan lo contrario, que los pasajes de la Septuaginta (LXX) y del Nuevo Testamento hablan de un grado de parentesco y no de literalidad, el trabajo de Ruiz ha sido considerado como conservador, la ventaja de éste es que analiza textos fuera de la Biblia, en griego y latín, como en las obras de Virgilio y Cicerón.
} 
"Hermano del Señor" resulta ser algo así como un título9, que se da a los familiares de Jesús, cuando entran en el seguimiento del Señor. Al no entender esto, Flavio Josefo habla de "hermanos de Jesús", porque no sabe interpretar el significado de "hermano del Señor". (García, 1995: 27)

Sin embargo, el problema no recae en el uso que Josefo hace de Señor y de Jesús, sino del término que él emplea de adelphós ("hermano"). Cabe preguntar sobre el uso de la expresión "hermano de Jesús" ¿Flavio Josefo conoció a Jesús y a Santiago? ¿Sabía del uso de "hermano del Señor" en la comunidad cristiana de Jerusalén? A la primera pregunta no se tiene una respuesta, a la segunda, Josefo recopila de primera o segunda mano su información, no se conocen sus fuentes al respecto de este punto, probablemente conocía inmediata o secundariamente al grupo seguidor de Jesús, más aún, conoció el papel del Sanedrín en la muerte de Jesús (el famoso testimonio flaviano). Josefo narra la muerte de Juan el bautista y la muerte de Santiago el "hermano" de Jesús (según el término que emplea Flavio Josefo), a manos del Sanedrín por trasgredir la Ley (Torá).

Hay otro aspecto para considerar, pues, según los críticos, este autor es una fuente inequívoca sobre el uso adelphós, y es que Josefo en algunos casos "corrige" a la Biblia hebrea para designar la diferencia entre el uso de anepsiós ("primo") y adelphós ("hermano") en griego (Antigüedades 1.19.4). Pero su construcción o corrección es bastante artificial e incluso exagerada. Es evidente que Josefo se dirige a un auditorio culto de lengua griega con palabras diferenciadas. Pero no hay una explicación del porqué la corrección o bajo que contexto la utiliza.

Para el caso de Hegesipo de Jerusalén (testimonio que recoge Eusebio de Cesárea en su Historia Eclesial 2.23.24; 3.19; 3.20 y 21; 4.22 aunque dichos pasajes son ambiguos) que sabe distinguir entre tío, primo y hermano, todos en griego, haciendo mención de Santiago el justo como "hermano del Señor" y a Judas (Lebeo) como "hermano según la carne". El término empleado "hermano según la carne" donde "carne" (sárx), que se diferencia de sóma ("cuerpo"), es extraño e insólito para hacer referencia a un lazo parental, hasta donde se tiene conocimiento, no hay texto bíblico que respalde dicha idea, ni que relacione por qué Hegesipo hace esa distinción. Da la impresión que la especificación es para suprimir equívocos, pero entonces surge la pregunta ¿qué diferencia hay entre que Santiago sea "hermano del Señor" y que Judas sea también "hermano" pero "según la carne"? qué acaso uno es más "hermano" en grado o parentesco, con la ambigüedad señalada cabe la posibilidad de plantear que hermano sea una 
connotación de hermandad a título, como propone García. Es curioso denotar que cuando los exegetas relacionan el uso de adelphós en los textos evangélicos haciendo referencia a Jesús, señalen que es "hermano carnal", pero cuando la palabra "hermano", sale de boca de Jesús, por ejemplo, en pasajes como Mc 6, 31-35; Mt 12, 46-50 los mismos exegetas reconocen que es en sentido figurado.

Sin embargo, los dichos de Jesús como Mt 12, 46-50 son, aunque en sentido figurado, mejor entendidos bajo el empleo de adelphós como "hermano", y no como "pariente" o "primo", por ejemplo en el evangelio de Mateo se tiene: "Y, extendió su mamo hacia sus discípulos, y dijo estos son mi madre y mis hermanos pues todo el que cumpla la voluntad de mi Padre de los cielos, ese es mi hermano, mi hermana y mi madre" (Mt 12, 46-50). Sin embargo, dicho criterio hace referencia a una hermandad espiritual y metafórica, más no se explica el uso de adelphós en sentido parental y biológico, como parecen usarlo Josefo y Hegesipo.

Por último, se analiza el uso que da Pablo de adelphós. Básicamente sus escritos son Ga, 1,19 y 1 Co 9, 5. El argumento es que Pablo hace referencia explícita de Santiago el "hermano" del Señor (Ga 1,19) y de los "hermanos" del Señor (1 Co 9,5), siendo que Pablo es conocedor del término adelphós y anepsiós, aunque Pablo nunca utiliza dicha expresión de anepsiós. Los exegetas que defienden dicha postura, suelen hacer mención de que en el Nuevo Testamento sí se distingue el uso de adelphós (hermano) y anepsiós (primo). Sin embargo, la palabra anepsiós solamente se usa una vez, dicho texto se encuentra en $\mathrm{Col} 4,10$, carta que está en entredicho que sea auténtica de Pablo; más bien, es una comunidad paulina que hace referencia a que Bernabé es anepsiós (primo) de Juan Marcos.

El empleo de adelphós por parte de Pablo cuando se dirige a los corintios (1 Co 9, 5) emplea un término que sólo aparece en dicho pasaje en todo el Nuevo Testamento, adelphoi tou kyrios ("hermanos del Señor"), la fórmula, "hermanos del Señor" (en plural) supone, según la crítica, a los "hermanos" que nombran los evangelios en Mt 13, 55-56; Mc 6, 1-3 (Santiago, Judas, José y Simón), aunque nunca se nombran en los evangelios como "hermanos del Señor" y sólo se hace referencia a ellos como "Jesús y sus hermanos". Eso tiene una sencilla explicación, pues, se muestra que éstos eran incrédulos del ministerio de Jesús, pero una vez exaltado y resucitado se convirtieron y creyeron en su mensaje. Sin embargo, el término Santiago el "hermano del Señor" que emplea Hechos de los Apóstoles y Gálatas, y que Flavio Josefo emplea como "hermano de Jesús" no deja de ser problemático, por la sencilla razón que no se sabe hasta que punto dichas expresiones recogen la estructura parental exogámica.

En síntesis, los datos históricos aplicando la exégesis muestran que el uso de adelphós es claro y con un sentido definido, el problema radica en el 
contexto en el que se aplica el término. Si se considera el uso del lenguaje y el cambio de hebreo o arameo al griego, que no es cosa menor, los datos se muestran menos claros y con ciertas ambigüedades. Se ha intentado ser lo más objetivo posible y el resultado es que adelphós denomina "hermano", literal y figurado, pero, en conjunto la formulación es ambigua y deja la impresión de que dicho término con respecto a Jesús no es del todo contundente e incluso aparece, en ocasiones, como artificial. Por eso buscar otras perspectivas que den cuenta de la ley exogámica en un entorno patriarcal es fundamental para poner en contexto los textos y en particular el empleo de adelphós. Antes de ello, hay que ver algunos casos particulares que refuerzan la idea de que hay ambigüedad con el empleo de $\alpha \delta \varepsilon \lambda \varphi \varsigma_{\text {. }}$

\subsection{El uso de Adelphós en los evangelios}

Para este apartado, hay que considerar algunos textos para problematizar los datos que parecen poco claros o bastante ambiguos, esto con el motivo de poner algunos elementos que no son explicados en sí por los mismos textos. Tomemos, por ejemplo, Jn 7, 1-10, en especial Jn 7, 2-5.8$10^{10}$.

Jn 7, 2-5.8-10, el cual menciona: "Al acercarse la fiesta judía de las Tiendas, le dijeron sus hermanos: 'Sal de aquí y vete a Judea, para que también tus discípulos vean las obras que haces, pues nadie actúa en secreto cuando quiere ser conocido. Si haces estas cosas muéstrate al mundo'. (Es que ni siquiera sus hermanos creían en él)". Después en los versículos 8-10 continúan con la respuesta de Jesús: “Subid vosotros a la fiesta. Yo no subo, pues aún no se ha cumplido mi tiempo'. Dicho esto, se quedó en Galilea, pero después que sus hermanos subieron a la fiesta, el también subió, aunque no manifiestamente, sino de incognito".

Antes de dar una interpretación del texto, hay que verificar su historicidad. De acuerdo a la Biblia de Jerusalén que en este caso sigue al exegeta R. Bultmman, dicho pasaje está fuera de contexto ${ }^{11}$, Jn 7, 2-9 es una glosa aparte, por lo cual el versículo 10 donde se menciona que Jesús subió a Jerusalén de incognito es una redacción del evangelista ${ }^{12}$. Se razona que está fuera de contexto Jn 7, 2-9 posiblemente se encontraba en Jn 4, 46-53 ya que en Jn 7, 2-9 supone que Jesús todavía no realizaba ningún milagro en contraposición de Jn 5, 1-9.

\footnotetext{
10 Aquí seguimos la traducción de la Escuela Bíblica de Jerusalén (2009).

11 También se puede verificar en Mateos \& Barreto (1982: 356-363).

12 Para este análisis, no tiene consecuencias graves si se admite la glosa o los versículos en conjunto o si la glosa es una redacción que se localizaba en otra parte, lo que importa es saber su historicidad o autenticidad, en especial de los versículos 2-5 y 8-9.
} 
En lo que respecta a su autenticidad o historicidad, aplicando el criterio de dificultad y de concurrencia o testimonio múltiple (Meier, 2012: 3234; Piñero, 2018), se puede decir con bastante certeza que los cumple. Aplicando el criterio de dificultad se cumple satisfactoriamente, al ser un texto donde se muestra la relación de desprestigio e incluso rechazo y mofa que sufre Jesús por parte de sus "hermanos", difícilmente un redactor cristiano pondría en situación tan embarazosa al Maestro. Para el criterio de recurrencia o testimonio múltiple, aunque dicho texto sólo aparece en el evangelio de Juan, no contradice, al contrario, refuerza la valoración familiar de Jesús, que es de desprestigio o incredulidad (Mc 3, 20-21), sabemos que Jesús no gozaba de aceptación por parte de su parentela. Por lo cual, tanto en Jn 7, 2-9 como en Mc 3, 20-21 tenemos un estrato original de la trasmisión oral que quedó redactado en distintas partes según el propósito de cada evangelista.

$\mathrm{Al}$ respecto de la narración que presenta el texto de Juan, la valoración es que da un dato concreto: el trato que recibía Jesús por parte de sus "hermanos", que es de mofa, de superioridad e incredulidad. Lo anterior, en una estructura patriarcal, es poco usual, insólito e inaceptable (Malina: 2002), esto en el supuesto que se acepte que Jesús tuvo "hermanos menores", ya que nadie pone en duda en ese sentido la primogenitura de Jesús. En el supuesto de que Jesús haya tenido uno o varios hermanos menores es insólito el trato que recibe por parte de ellos, ya que el primogénito al ausentarse el padre recae todas las complacencias ${ }^{13}$.

Los evangelios señalan a Jesús como hijo de María (Mt 1,21; Lc 2,51; Mc 6, 3; Hch 1, 14) y como hijo de José o del "carpintero" (tektón), su padre (Mt 1, 23-24; 13, 55), sin embargo, nunca se señala a los "hermanos" de Jesús como hijos de María, ese aspecto puede ser respondido diciendo que era una forma usual de no designar a los hijos por medio de la madre, sino, sólo por el padre. Pero tampoco son señalados como hijos de José o hijos del "carpintero", más aún, de acuerdo con los evangelistas, a los hermanos de un mismo padre, en total concordancia con la estructura patriarcal, se les designa como "hijo de tal padre", por ejemplo, Santiago el de Alfeo, Judas de Santiago, Santiago el de Zebedeo o Santiago y Juan los hijos de Zebedeo (Mc 3, 17-19; Hch 1, 13; 10, 35; Mt 10, 1-4; Lc 6, 12-16). A lo anterior hay que señalar que también se emplea el término referido a las mujeres cuando se la relaciona con su esposo, como María la de Clopás (Jn 19,25).

13 Malina (2002) ha descrito los patrones de conducta en las sociedades mediterráneas antiguas donde el parentesco es la base de la sociedad, habría que hacer un estudio más puntual teniendo en cuenta los trabajos de Moxnes, sobre la convulsión que creo Jesús al modelo del parentesco judío. 
En suma, el balance general es bastante pobre y ambiguo. Hay que saber distinguir dos fases o momentos del estudio de la parentela de Jesús y la relación con ella misma, por un lado, tenemos las intenciones de Jesús dentro de la misma familia, y el rechazo, incredulidad, mofa, incomprensión, etc. que sufrió por parte de su familia, y en una distinta fase los lazos sanguíneos familiares. Sobre este último aspecto es casi imposible señalar una conclusión probable, una vez revisados los textos a fondo, por la sencilla razón de que se prestan a distintas interpretaciones y dejan muchos aspectos sueltos y sin resolver, no hay que ir muy lejos, solo basta leer los textos para ver o resaltar las incógnitas, como por ejemplo ¿por qué no se nombran a los "hermanos" y "hermanas" de Jesús con respecto a los nombres de los padres?, ¿Por qué Jesús se ve interpelado por sus familiares?, ¿Jesús se insertó en una familia exogámica extendida y cuál era su rol? Estas y otras preguntas son pertinentes, pero aunque los evangelios nos dan datos, por sí mismos no nos dan las respuestas. Con esto damos paso al siguiente apartado para dar una tipificación y sacar algunas implicaciones del rol familiar.

\section{LA ESTRUCTURA PATRIARCAL COMO INSTITUCIÓN ECONÓMICA Y FAMI- LIAR}

La génesis de la estructura antropológica parental en el Nuevo Testamento hay que identificarla en sus raíces judías y hebreas antiguas, hay algunos elementos que la caracterizan o la identifican, sin duda, dicha característica es el patriarcado exogámico. El desarrollo del patriarcado en su forma mítica o histórica es un elemento que forma parte de la historia de Israel. Al respecto hay dos aspectos a señalar, 1) en base a la historia de clan, familia y tribu y 2) respecto a la economía antigua ${ }^{14}$ y su forma de estructurarse con la familia-tribu y la religión de los padres (Douglas, 2006; Dussel, 1969).

Sobre los orígenes del antiguo Israel y su desarrollo histórico (Del Olmo Lete, 2010; Dussel, 1969; Kessler, 2013), leyendo el Pentateuco y a lo largo de la Biblia hebrea se pueden diferenciar un régimen patriarcal, de clan y de tribu, siendo la estructura familiar patriarcal la base social. En ese sentido el régimen patriarcal se organiza: "el jefe es el padre, $b a$ 'al (dueño) de la mujer, hijos, siervos y animales. Después de la baît (casa o pequeña agrupación) existe la mishpajáh (familia o clan), para unificarse, por último, en la shébet (tribu), que posee comunidad de sangre, y es la descendencia de un mismo antepasado mítico." (Dussel, 1969: 52)

14 Sobre la economía antigua de Palestina en el siglo I d.C se retoman los estudios de Miquel (2010); Hoornaert (1996); Stegemann \& Stegemann (2001) y Kessler (2013). 
$\mathrm{Al}$ respecto, es importante señalar que si bien la familia patriarcal es la base sus ramas se extienden al clan y la tribu. En torno al patriarca se reúnen los hijos y las esposas de los hijos. En ese sentido, el núcleo familiar extenso es un elemento que se encuentra en muchas otras tribus y pueblos antiguos, la organización en torno al clan o familia patrilineal extendida se encuentran en grupos tanto indoeuropeos, semitas y algunas tribus totémicas. Así ya lo identificaba la etnología a principios del siglo XX:

Los individuos que lo componen [al clan familiar] se consideran unidos por un vinculo de parentesco que es de índole muy particular. El parentesco no proviene del hecho de que mantengan unos con otros relaciones definidas de consanguinidad; son parientes por el sólo hecho de llevar el mismo nombre [del clan]. No son padres, madres, hijos o hijas, tíos o sobrinos, entre sí, en el sentido que actualmente damos a esas expresiones; y sin embargo se consideran unas a otros como si formaran una misma familia, numerosa o reducida según las dimensiones del clan [...] Y si decidimos que se consideran como miembros de una misma familia, es porque reconocen tener unos hacia otros deberes idénticos a los que en todo tiempo han recaído sobre los parientes: deberes de asistencia, de vendetta, de duelo [...] etcétera. (Durkheim, 2012: 154)

Lo anterior es muy importante al momento de clasificar los miembros de una familia, queda claro que los estándares lingǘsticos de la familia occidental no son apropiados. Ya que no sólo en los pueblos semitas se han identificado patrones similares de lo que se considera familia extendida. Para el caso de los semitas la consanguinidad se define en torno al patriarca, haciendo que los tíos sean padres de los sobrinos y los sobrinos los vean como tales; en tanto los primos se ven como hermanos (Aranzadi, 2008: 403-410).

Este elemento, que es el problema principal de esta investigación, ha sido reconocido por los lingüistas y antropólogos, que se enfrentaron con problemas insolubles, desde el punto de vista filológico, al intentar clasificar las familias de los pueblos antiguos y algunas tribus aborígenes. Los etnólogos se percataron que, en torno a la clasificación parental, donde más se aleja la relación de sangre, el término que más difícil se presenta de clasificar, por su polivalencia y empleo, es sin duda, con los lazos parentales de "hermano". Se dieron cuenta que los sistemas de clasificación occidentales comúnmente aceptados y difundidos, no aplicaban para dicho empleo del término en los pueblos y tribus estudiadas.

Se percataron que en el estudio de la parentela exogámica extendida el empleo de "hermano" tenía una connotación mucho más amplia, "los hermanos del padre son considerados como padres; los hijos de hermanos son hermanos entre ellos y no primos" (Aranzadi, 2008: 406), dicha visión 
es totalmente coherente con los pueblos semitas. Como lo denota el lingüista Benveniste y los estudios parentales: "Los problemas que la filología no puede resolver por sí sola halla su solución en la estructura del parentesco exogámico" (Benveniste, 1969, citado en Aranzadi, 2008: 403).

Por lo cual el señalar la estructura familiar es una tarea crucial, no sólo en su aspecto parental sino también en su aspecto socioeconómico ya que es una estructura indisoluble familia-economía doméstica. En ese sentido, las características de la familia patriarcal son básicamente 3,1$)$ el varón permanece en su grupo familiar en tanto que la esposa debe dejar a su familia. Se conoce que para la familia patriarcal extendida la familia se reúne en torno al padre, sus hijos y los hijos de éstos con sus mujeres, una vez muerto el padre, los hijos reciben en herencia y se dispersan (González, 2017: 33). Sin embargo, la familia queda custodiada por los parientes varones del padre (difunto), 2) la primacía del hombre en definir y trasmitir las tradiciones y las formas de producir, incluyendo las formas de mantener o desprenderse de las mujeres, ya que de dichas prácticas se transmitirá la herencia familiar y 3) si no hay varones, las hijas contraen matrimonios endogámicos con parientes del padre.

En lo que respecta a la relación familia y la economía antigua, se sabe que la economía y sociedad en la cual el imperio romano funcionaba y por ende todas sus provincias conquistadas, entre ellas el pueblo judío, estaba basado en el sistema esclavista con una estructura agraria, en donde la población rural cargaba con el mayor peso del funcionamiento de la estructura productiva. También, se sabe que la "célula" de producción básica de las sociedades agrícolas es la unidad doméstica (oikos en griego, hogar, casa) y en particular que: "La familia patriarcal es el grupo de solidaridad más básico y fundamental de todas las sociedades preindustriales que integran el Imperio romano" (Miquel, 2010: 67). Siendo así, la sociabilización coincide con el grupo familiar, para lo cual, es de vital importancia para la institucionalización de la unidad doméstica el comportamiento de reciprocidad y solidaridad. Prácticamente quien carece de familia está a la merced de la esclavitud, la inanición y marginación. Entre más miembros haya en una familia existe una mayor posibilidad de éxito para la economía de la misma.

Lo anterior no es circunstancial, es la expresión básica de la estructura patriarcal y agraria ${ }^{15}$, si se considera que al coincidir la estructura económica con la estructura familiar, se sostendrá y reproducirá el resto de la sociedad incluyendo a la clase política y religiosa dominante (Stegemann

$15 \mathrm{Al}$ respecto hay que tener en cuenta los estudios de las sociedades preagrarias, nómadas y agrarias; véase, Sahlins (1983). 
\& Stegemann, 2001). Hay que aclarar que no se está realizando una correlación entre la estructura patriarcal y la estructura económica, pues la unidad doméstica como unidad económica e histórica se extiende de manera que no sólo se remite a un sistema agrario o esclavista, pero que sin duda se acentúa con mayor fuerza en las sociedades agrarias ${ }^{16}$.

La confrontación y dominación que vivió el pueblo judío en tiempos de Jesús se reflejó también en expresiones religiosas como la apocalíptica, síntoma de que se vivía una crisis social, ante dicha crisis la respuesta de solidarizar los patrones familiares era una forma de soportar las situaciones de explotación y dominio. Por lo cual, la situación de marginación se acentuaba con la desigualdad del bien más preciado, la tierra. Las grandes extensiones pertenecían a la familia herodiana, pero también la clase sacerdotal (sobre todo los saduceos) poseía propiedades extensas de tierra. La carga impositiva era especialmente en especie, pero también monetaria, aunque el uso de la moneda no era común sobre todo en zonas rurales como en Galilea de donde provenían Jesús y sus seguidores.

En suma, la situación social y económica de Judea en tiempos de Jesús era endeble, por una parte existía una clase privilegiada (clase gobernante y sacerdotal) con la cual coexistía una sociedad en situaciones más endebles que sostenían la dinámica económica y tributaria, dinámica que se fundamentaba en la familia patriarcal como base de la estructura de producción y reproducción de la misma, por lo cual, las personas que no tenían familia, o eran excluidas de la misma por factores religiosos, sociales o políticos, eran las personas más vulnerables, incluso los esclavos no pasaban tantas penas como estas últimas.

En todos los estratos juega un rol importante la familia patriarcal, siendo que la falta de una familia con referente a la línea del varón significa estar excluido y poner en riego el mínimo vital o caer en la esclavitud por endeudamiento. La familia en tiempos de Jesús se encontraba en una perspectiva de sometimiento y dominación. Para ilustrar esta última idea se presenta a continuación una clasificación de las clases sociales en tiempo de Jesús (figura 1).

\footnotetext{
16 Para un análisis histórico sobre la unidad doméstica como institución de comportamiento económico, remitimos a la obra de Polanyi (2017). La característica de la obra de Polanyi es la perspectiva antropológica, aspecto que se considera como economía "sustantivista", que hace referencia al sustento del hombre desde un marco axiológico y antropológico. También, la obra de Mirón (2004: 61-79), realiza una reflexión histórica sobre la unidad doméstica, en donde confluyen aspectos de lazos económicos y biológicos, aspecto que, también, confluyen con la antropología del parentesco que se subdivide en parentesco biológico y social.
} 
Figura 1. Estratos sociales en Judea siglo I d.C. (campo y ciudad).

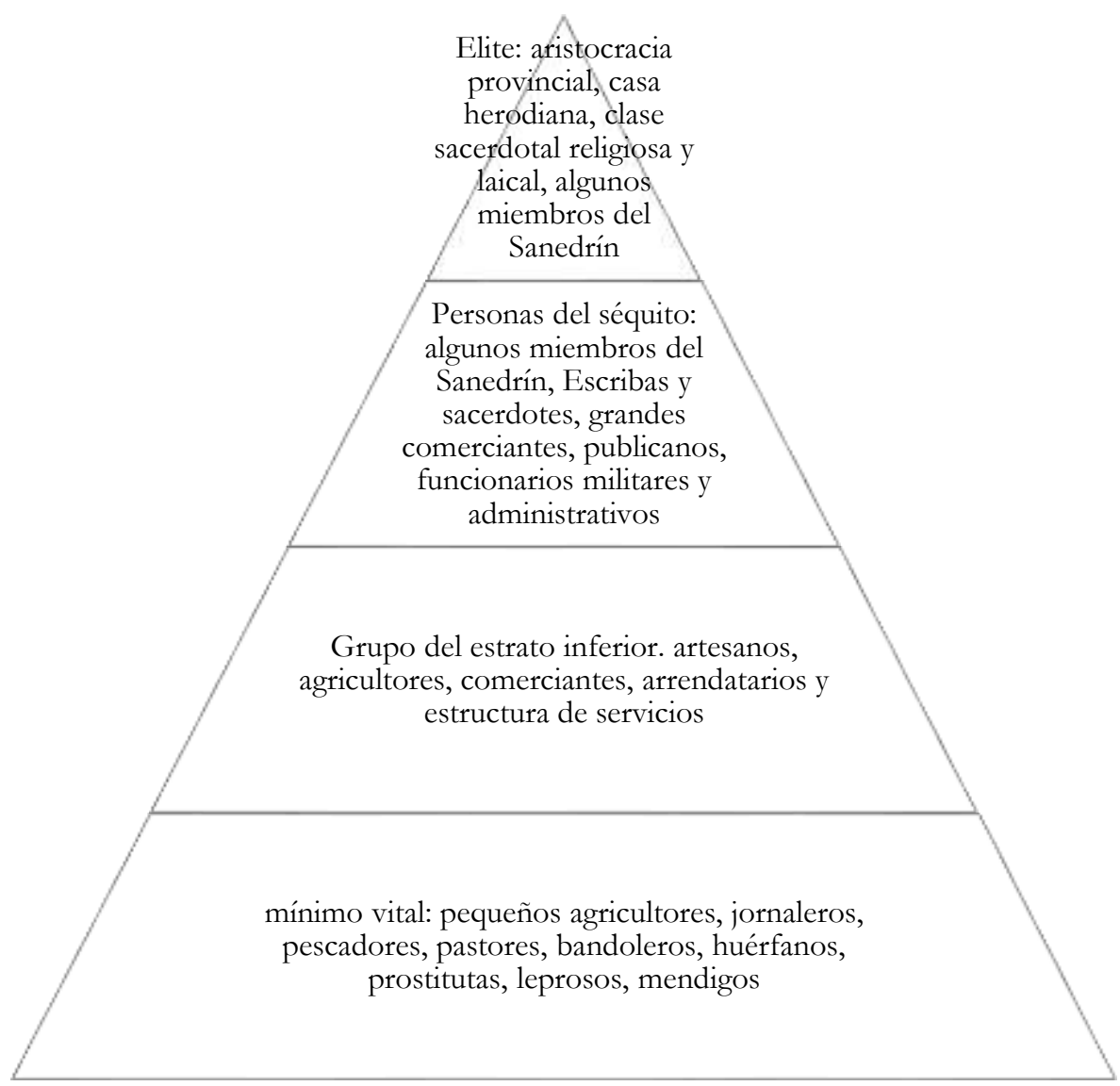

Fuente: elaboración propia con base en Stegemann \& Stegemann, 2000.

Una revisión crítica a la estructura familiar en tiempos de Jesús, la ha presentado Moxnes $(1997 ; 2005)$ quien ha señalado que el movimiento que generó Jesús fue antisistémico, en el sentido de que se propuso reformar la estructura patriarcal, tanto en sentido familiar como socioeconómico. Moxnes comenta que la crítica de Jesús al patriarcado se dirige al prototipo de hombre dominante, pues, enaltece a los eunucos y marginales sexuales.

Hasta aquí es momento de hacer un balance. Se han señalado dos aspectos para caracterizar la parentela de Jesús: el parentesco patriarcal exogámico extendido y la estructura de la unidad doméstica. Si con esto basta para empezar a resolver el problema, con los datos del evangelio para poner a Jesús dentro de una estructura parental, se podría decir que la relectura de los textos necesitan reinterpretarse. 
Qué se puede decir. Sólo hay probabilidades y plausibilidades con mayor o menor grado de certeza, porque no hay datos que señalen de forma directa una hipótesis. Esto puede ser muy desilusionante para algunos, sin embargo, se puede jugar con varios posibles escenarios, aunque para algunos pueda representar un ejercicio especulativo, pero es necesario para saber los límites del enfoque y sus posibilidades, por ejemplo, se puede sugerir que Jesús fue el único hijo de María y José, históricamente es plausible. Esto se considera en base a que no se designa a los otros "hermanos" de Jesús con respecto ni a José ni a María, muestra probable que los "hermanos" son de otro matrimonio de la línea patriarcal, es decir, son pri$\operatorname{mos}^{17}$. Sin embargo, también se podría aludir al respecto que José tuvo antes otros bijos, antes de contraer nupcias con María, lo anterior históricamente también es probable, sin embargo, las dos sentencias son especulación, porque no hay ningún dato histórico directo que abone a una u otra sentencia de forma precisa ${ }^{18}$.

Otro escenario puede ser que José murió de forma prematura o al menos cuando Jesús era muy niño, pues, no vuelve a parecer en los relatos, sólo se vuelve hacer referencia como José el carpintero padre de Jesús $(\mathrm{Mt}$ $13,55)$ haciendo un eco del recuerdo ${ }^{19}$. De acuerdo al parentesco exogámico patriarcal, María no tenía que casarse con algún hermano, tío o algún varón de la familia de José (línea patriarcal) para perpetuar el linaje patriarcal, pues, Jesús era el primogénito (al respecto no hay problema en usar primogénito, aunque haya sido unigénito). Se explica, que Jesús y María ya eran pertenecientes al núcleo patrilineal extendido, al morir José y al empezar Jesús a predicar, María queda subordinada y a disposición de los varones de la familia de José, en ese sentido hay que recordar que las mujeres no pueden estar en público sin la compañía de un varón. En ese sentido Jesús es perteneciente a una familia patriarcal exogámica extendida, aspecto común en la época, por lo cual, asignar a sus parientes como adelphós, âh, âhâ "hermano(s)" no implica nada metafórico o sospechosos, es simplemente la forma usual de señalar a los miembros de una familia exogámica extendida.

Es decir, sus "hermanos" podrían ser sus "primos" de acuerdo a nuestro sistema de clasificación parental, y lo anterior es casi una certeza históricamente hablando, porque es lo común de la estructura familiar de

17 Considerando la clasificación parental occidental, pero que no corresponde a la lógica de los textos mismos.

18 Aquí no se consideran los relatos de la anunciación en Lucas y Mateo, para poder hacer un balance lo más neutral posible, considerando también que habría que probar su historicidad o los extractos históricos.

19 Luz (2001: 509-12) acepta, también, como posible dicho aspecto. 
aquellos tiempos designar como hermanos a los miembros de la familia patriarcal exogámica extendida.

Por lo cual, el término usado en el Nuevo Testamento de adelphós no contradice la clasificación parental, el problema es cuando se toma con una literalidad ajena a la antropología parental exogámica patriarcal. Sería extraño usar la palabra anepsiós (primo), pues no responde a la lógica de la estructura antropológica parental semita ${ }^{20}$.

\section{CONCLUSIONES}

Los textos que se recogen de los evangelios no pueden dar por sí una solución a los lazos parentales de la época de Jesús, de no considerar el análisis antropológico parental, se llega a un callejón sin salida. Parentalmente Jesús pudo estar inserto en una familia exogámica extendida como era común en ese tiempo en Israel, de hecho es lo más seguro, ya que desde un punto de vista tanto teológico como familiar y económico, la extensión familiar era signo de bendición, seguridad y status; pero eso no significa aceptar o correlacionar de forma automática que haya tenido hermanos biológicos, una posible respuesta de ello es que José falleciera de manera prematura o por ancianidad cuando contrajo nupcias con María, una vez dado a luz a Jesús, y con ello tanto Jesús como María convivieran con los demás miembros de la familia patrilineal, lo anterior es también históricamente probable y no perturba los datos que se tienen. Para algunos puede parecer bastante especulativo, pero racionalmente e históricamente es tan probable como que haya tenido hermanos carnales, como la mayoría de los exegetas, esto último, lo consideran.

Lo que sí cuestiona los lazos parentales con algunos datos de los evangelios y que no se han podido estudiar en este trabajo, son los hechos de por qué Santiago toma posesión de la Iglesia principal de Jerusalén, siendo que Jesús asignó a Pedro como principal, por qué Jesús recibe burlas de su parentela, etc. Esto indica, que probablemente Santiago el "hermano" del Señor era mayor que Jesús, por lo cual en la línea patriarcal toma posesión de la descendencia, al morir y resucitar Jesús, sobre Pedro que era ajeno al núcleo patriarcal. Otro aspecto a considerar son la relación Jesúsparientes, Jesús pudo reformar el patriarcado, como Moxnes propone, pero se puede también considerar que los insultos recibidos por su parentela no corresponden a Jesús como primogénito sino como un miembro

20 No se trata de estadística como parece sugerir Meier (1998) y Luz (2001: 509 nota 15), al decir que solo existen unos escasos testimonios donde hermano, adelphós, se usa como sobrino o primo. 
inserto en una familia patriarcal exogámica extendida, es decir, con varones mayores y menores, que hoy denominaríamos como primos y tíos, que rehúye de las actividades del rol familiar subordinado para abrirse a una familia espiritual, el reino de Dios.

Más que conclusivo este estudio ha intentado ser provocativo y reflexivo. Creemos también que dicha investigación puede prestar material para la reflexión hermenéutica y teológica. Mejor aún poner en igualdad de circunstancias en los estudios bíblicos para aquellos, aún dentro del catolicismo, que consideran que la cuestión está zanjada a favor de la literalidad de adelphós, pero como se ha intentado demostrar, si es correcto lo aquí presentado, hay más preguntas que certezas e históricamente es igualmente racional, y no eclesiástico y político, considerar a Jesús de Nazaret como unigénito de María y José.

\section{REFERENCIAS}

Aranzadi, J. (2008). Introducción bistórica a la antropología del parentesco. Madrid: Editorial Universitaria Ramón Arces.

Brown, R. (Ed.) (1978). Mary in the New Testament. Filadelfia-Pensilvania: Fortress. Del Olmo, G. (2010). Origen y persistencia del judaísmo. Estella: Verbo Divino.

Douglas, M. (2006). El Levítico como literatura. Una investigación antropológica y literaria de los ritos del Antiguo Testamento. (J. Arrambide \& M. Pino, Trads.). Barcelona: Gedisa.

Durkheim, É. (2012). Las formas elementales de la vida religiosa. El sistema totémico en Australia (y otros escritos sobre religión y conocimiento) (J. H. Ruíz, Trad.). Ciudad de México: Fondo de Cultura Económica-UAM-Universidad Iberoamericana.

Dussel, E. (1969). Humanismo semita. Estructuras intencionales radicales del pueblo de Israel y otros pueblos semitas. Buenos Aires: Editorial Universitaria de Buenos Aires.

Escuela Bíblica de Jerusalén (2009). Biblia de Jerusalén. Bilbao: Desclée De Brouwer.

García, J. C. R. (1995). Mariología. Madrid: Ediciones Cristiandad.

González, S. (2017). Antropología del parentesco en Babilonia. Estudio de los grupos consanguíneos y residenciales en el periodo paleobabilónico. (Tesis doctoral). Barcelona: Universidad de Barcelona, Facultad de Filología.

Hoornaert, E. (1996). El movimiento de Jesús. Ciudad de México: Ediciones Dabar. Josefo, F. (1997). Antigüedades judías. (J. Vara, Ed.). Madrid: AKAL.

Kessler, R. (2013). Historia Social del antiguo Israel (M. Olasagasti, Trad.). Salamanca: Ediciones Sígueme.

Luz, U. (2001). El evangelio según San Mateo (Vol. II). Salamanca: Ediciones Sígueme.

Malina, B. J. (2002). El mundo social de Jesús y los evangelios (J. M. Lozano-Gotor, Trad.). Santander: Salterrae. 
Mateos, J. \& Barreto, J. (1982). El evangelio de Juan. Análisis lingüístico y comentario exegético. Madrid: Ediciones Cristiandad.

Meier, J. P. (1998). Un judio marginal (Vol. I; S. Fernández, Trad.). Estella: Verbo Divino.

Meier, J.P. (2012). Un Judio Marginal (II/1; S. Fernández, Trad.). Estella: Verbo Divino.

Miquel, E. (2010). El aspecto histórico y sociocultural. En R. Aguirre (Ed.), Así empezó el cristianismo (pp. 49-99). Estella: Verbo Divino.

Mirón, M. D. (2004). Oikos y oikonomia: El análisis de las unidades domésticas de producción y reproducción en el estudio de la Economía antigua. GERIÓN Revista de Historia Antigua, 22(1), 61-79.

Moxnes, H (1997). What is family: problem in constructing early Christian families. En M. Halvor (Ed.), Constructing early Christian families (pp. 13-43). London: Routledge.

Moxnes, H. (2005). Poner a Jesús en su lugar. Una visión radical del grupo familiar y el Reino de Dios (C. Bernabé, Trad.). Estella: Verbo Divino.

Piñero, A. (2018). Aproximación al Jesús histórico. Madrid: Trotta.

Polanyi, K. (2017). La gran transformación (G. Chailloux, Trad.). Ciudad de México: Fondo de Cultura Económica.

Ruiz, A. (1994). Los hermanos de Jesús y la iconografía de Moisés. EPOS. Revista de Filología, (10), 51-67.

Sahlins, M. (1983). Economía de la edad de piedra (E. Muñiz \& E. R. Fondevila, Trads.). Madrid: Akal.

Stegemann, E. \& Stegemann, W. (2001). Historia social del cristianismo primitivo. Los inicios en el judaísmo y las comunidades cristianas en el mundo mediterráneo (M. Montes, Trad.). Estella: Verbo Divino.

Tuggy, A. E. (1996). Léxico Griego-Español del Nuevo Testamento. Alabama-El Paso: Editorial Mundo Hispano. 